Micuea. Arteche.

\title{
NOTAS PARA LA VIEJA Y LA NUEVA POESIA CHILENA
}

Quiero hacer algunas advertencias, antes de comenzar la lectura de este trabajo.

Procuré sintetizar hasta donde me fue posible el texto de mi charla, pues pese al titulo de ella tuve que extenderme para presentar un acopio de pruebas que sostuvieran mi planteamiento. Todo esto necesitó. naturalmente, un desarrollo que hubiera querido mis breve.

Con el objeto de no interrumpir el curso de la relación, no voy a lecr las notas que la acompañan y amplian su sentido. Las he dajado para el debate que se abrirá una vez terminada la lectura.

Quicro advertir, además, que no pretendo dar leyes fijas para la creación poética: pues, de hacerlo, no sería sino un pedante. Pero creo que cl poeta debe conocer, en primer lugar, el idioma que escribe -sus limites y sus riquezas-, hito descle donde debe partir, no importa las significaciones históricas, politicas, religiosas y sociológicas que aporte su personal modo de mirar el mundo. Intento, pues, partir de ese punto, y ad. vierto que lo hago descle la poesía: no soy nì un filólogo, ni un lingüista, ni un profesor de retórica. Pero me he preocupado (con mis limitaciones) por enfrentar el fenómeno de la lengua que hablamos en América, cosa, me parece, de primordial importancia para un poeta.

Advertiré, además, que mi posición no sólo responde a la honradez con que he tratado de esbozar mi pensamiento. Trato de probar lo que plantco. Fs posible que no lo pruebe todo. La pocsía no tiene explicación. Podemos, si, acercarnos a su misterio, siempre que tengamos bien en cuenta que la inteligencia y el rigor del poeta no hacen la poesia, aunque son, entre otras cosas, sus mejores apoyos.

Agregare, en fin, que los ejemplos de que me servi para sustentar mis ideas, no fueron tomados al azar. Si mís adelante ustedes desean dialogar sobre otros casos (siempre que ellos no se salgan del terreno en el cual voy a colocarme), no tendré inconveniente en hacerlo, pues me ayudarán a esclarecer, confirmar o echar por ticrra lo que sostengo.

No me refiero, en fin, a Gabriela Mistral. Su poesía constituye para mí un caso extraño: espera aún el investigador que trate de aproximarse a su centro (Gastón von dem Bussche lo ha intentado hacer recientemente). 
No puedo, pues, aplicar a ella las idçs que empleo al referirme a otros poetas. Su riqueza expresiva, su sentido de la estructura, entre otras cosas, me impiden hacerlo.

Vengo a aprender, y no a cortar puentes. Por lo demás, este "Encuentro de Escritores" no pretende otra cosa.

I.

Es posible que al esbozar algunas de las líneas seguidas por la nueva poesía chilena (y llamo nueva a la de mi generación: con más exactitud, a la que comprencle los poetas que hoy tienen entre veintidós y treinta y dos años). lo haga no a una orilla del rio, sino en medio de él. En otras palabras, es posible que este esquema no sea completamente imparcial. Pero siempre es mejor plantear las cosas de viva voz, y no cerrar la boca, contentándose con algún comentario a las espaldas de otros poetas, o detrás de los parapetos donde suelen encerrarse los críticos. Estas notas deben tomarse, pues, como una ayuda para comprender cuáles son los caminos que mi generación sigue, cualles son sus logros y sus fracasos y de qué manera responde a las generaciones anteriores. Creo, por lo demás, que un núcleo nuevo de poctas - no importa cuál sea su significación en el movimiento lírico de un paísdebe dar cuenta de lo que pretende hacer, y en este hacer entiendo no sólo su actitud poética.

Más de alguien me dirá que el poeta debe responder ante los demás sólo con su poesía, y que es ella la única que puede dar testimonio de su actitud ante las cosas. Es cierto. A poema publicado debe seguir, cuando existe un lector y una critica inteligentes, el comentario que más tarde esclarecerá la posición presentada por una lírica. Pero el poeta puede expresarse por otros medios que no sean los de la poesia, aunque sólo ésta le satisfaga plenamente. Estos medios le servirán, si no para clarificar su sesgo, por lo menos para demostrar que su personal modo de mirar el mundo nada tiene de arbitrario.

Voy, pues, a indicar unas direcciones, sin pretender que ellas penetren en el centro mismo de la poesia, en su misterio, cosa imposible por inefable.

II.

Ante todo el diálogo. Diálogos entre nosotros: ensayistas, dramaturgos, criticos, novelistas, cuentistas y poetas. No el diálogo enmascarado en las 
comidas. Tampoco el diálogo del comentario benévolo en las páginas de una revista o en las de un periódico. Si el diálogo que no teme ir contra la corriente, aunque esa corriente sea la de otras generaciones

Siempre he tenido la impresión de que viejos y jóvenes poetas (hablo en un sentido cronológico) se guardan una respetuosa cortesia. ¿Que no siempre se han cuidado las espaldas los jóvenes y los viejos? ¿Que las promociones anteriores a la mía, por ejemplo, se lanzaron ataques, réplicas y polémicas? Pero no es ése el diálogo necesario. Muchas veces no fue tal: fue un vocerio desenfrenado en que los insultos corrian a parejas con las posiciones cerradas. Que un poeta reciba aguijonazos durante su carrera, es cosa inevitable y, además, necesaria. Pero que los poetas, para acentuar el campo de su acción, tengan que recurrir a los dicterios y a los insultos, es algo que nada tiene que ver con la función principal del diálogo: es decir, expresar los puntos de vista de las distintas posiciones para tratar de llegar, si es posible, a un norte amplio donde quepan todas las miradas.

Ni cortesía de comensales, ní vocerio de malón.

III.

Ahora bien, ¿dónde empieza el campo de mỉ generación?, ¿qué es lo que hasta ahora ha dado? ¿qué pretende entregar a los años venideros?, ¿dentro de qué límites se mueve?, ¿̨cuál es su responsabilidad ante el fenómeno poctico?

Voy a responder a estas preguntas haciendo, si, una salvedad: los puntos de vista que desarrollaré aquí son compartidos en general por mis compañeros de generación, con los cuales he conversado durante muchas horas estos problemas, y entre los cuales existen diferencias no sólo poéticas - lo bastante marcadas para que, por supuesto, yo me haya atrevido a hablar de generación-, sino también desigualdades politicas y religiosas. Lo que ocurre es que, ante problemas importantes de la poesia y frente a la cosecha que nos dejaron los poetas mayores - esto es, los que como Neruda, Huidobro, De Rokha, Diaz Casanueva y Rosamel del Valle, ya pasan del medio siglo- reaccionan casỉ de una misma manera, y lo hacen, esto es lo importante, no solo con responsabilidad ante teorias poéticas sino con rigor frente a su quehacer de poetas: ante el poema. 
IV.

No cabe ahora hacer la historia de la poesía chilena contemporánea, en sus cincuenta anos de este siglo. Ni cabe tampoco (puesto que otros lo pueden hacer, y lo han hecho, mejor que yo) esbozar el panorama de nuestra lírica, a partir, por ejemplo, de Carlos Pezoa Véliz. Ni sostener que, pese a ser la poesfa chilena la más importante en el campo vasto de la lengua española de América, sea la más alta en el territorio, muchísimo más amplio, de la lírica occidental, como han pretendido algunas personas, guiadas por un afán nacionalista que nos perjudica más que nos favorece.

Pues bien: a través de libros publicados entre 1945 y 1955, aparece lo que ahora puede llamarse poesía nueva o joven: última expresión de nuestro desarrollo poético.

¿Cómo vemos nosotros, en líneas generales, lo que los poetas mayores realizaron y siguen realizando? Será ésta, pues, una manera de explicar, a contrario sensu, lo que hasta ahora han hecho mis compañeros o, por lo menos, lo que desean hacer.

v.

Muchas veces he oidlo decir que los poetas jóvenes chilenos carecen de audacia. Por audacia entendian algunas personas-después de las oleadas que arrojó sobre el campo de la poesía chilena la generación del año veintela supuesta retórica de los poetas nuevos, retórica que comenzaba en la forma y terminaba en el contenido poético (yo no establezco separación entre ellos), el cual o tocaba problemas demasiado menores, 0 , simplemente, no alcanzaba a rozar temas que eran muchos más importantes para la poesía: por ejemplo, el trabajar con elementos del subconsciente, el disponer, dentro del poema, de teorías filosoficas, la supuesta falta de responsabilidad frente al oficio o ante las libertades que esa generación había traído, esto es, la libertad creadora absoluta, expresada a través del verso libre. Nos acusaban, en fin, de no haber sabido aprovechar la lección de libertad que -según cllos- nos habian dado los poetas mayores, y de haber utilizado, en algunas ocasiones, la regularidad estrofica, y hasta la rima. Los poetas nuevos cran tímidos, no reaccionaban contra sus predecesores, no escribian largos artículos polémicos contra los viejos poctas: eran, en fin, gente pasiva, y algunos de sus poemas se apoyaban demasiado en la tradición hispánica, sin mirar ni recrear lo que tenian en su contorno americano. Por un lado, los 
que trabajaron con técnicas surrealistas', nos llamaron conscrvadores: no se explicaban por qué para nosotros tenia una gran importancia la cstructura del poema, y, en general, la arquitectura de la obra, y por qué nos atreviamos a "contar" algo en la poesia; por otro lado, nos trataban de "escapistas" o mejor de "fugitivos". porque, según ellos, eludiamos los "candentes" problemas sociales y no seguiamos las aguas del realismo socialista. En otras palabras, los nuevos poetas chilenos eran blandos, intimistas, menores, se aferraban a la forma y carecian de las virtudes de sus mayores.

VI.

Tal vez nuestra promoción en el desarrollo de la poesía chilena será considerada como un núcleo que, al enfrentarse al fenómeno poétíco, estuvo provisto no sólo de una seriedad ante el oficio, ante el rigor idiomático (que no se explica con teorias o con artes poéticas, sino que se demuestra con un hecho concreto: el poema) : también actuó con la conciencia de que la estructura, el control y la presión a que debe estar sometida la poesía son tan importantes para ésta como el ejercicio que el pensamiento realiza en lo mís profundo de la composición poética. Si hiciéramos un balance de nues. tros poemas más valiosos, llegariamos a la conclusión de que los nuevos poetas de Chile no se concentraron en el uso de determinado metro. Tanto Rosenmann Taub, Uribe Arce como Rubio utilizan indistintamente los cauces del verso libre o los de metros tradicionales. $Y$ cuando se produce, por una especie de niebla invisible que rodea un núcleo generacional, un fenómeno de esta naturaleza, creo que el deber del crítico, y también del poeta mayor, es el de comprender, en primer lugar, que tal posición no nace sólo de razones formales. Ni el verso libre ni el tradicional significan nada sin una actitud espiritual interna, bien precisa y concreta. El verso libre no da patente a ningún poeta para sentirse revolucionario ni vanguardista. "Sólo un mal pocta - dice Eliot- podría acogerlo como una liberación de la forma"z. Creer que tal verso es el único cauce sobre el cual puede moverse una poesia, por muy americana que pretenda ser, es limitar el ámbito de

"Empleo la palabra "surrealismo" para referirme al movimiento francés, que, en este caso, influyó sobre los integrantes del grupo Mandrágora. La forma "superrealismo" - como lo ha indicado un ensayista español- queda para la tendencia que imperó por algunos años en la poesía española.

s'De hecho-dice T. S. Eliot- el mal poeta es generalmente inconsciente donde debería ser consciente, y consciente, donde debería ser 
ella. Como crecr, por el contrario, que la poesía pucde sólo aceptar los campos métricos tradicionales. La toma de contacto con los metros antiguos no significa una actitud conformista, ni siquiera una actitud de acomodo. Los jóvenes poetas cuentan con el verso libre, frente al cual tíenen absoluta libertad de elección: es un instrumento tan útil como el soneto. Sin embargo, nosotros no creemos (lo que no sería sino un prejuicio), que sea la única forma dentro de la cual puede expresarse un contenido podtico contemporánco.

De esta manera, pues, y dentro de cualquier forma, lo que se hace importantísimo para los poetas jóvenes no es sólo la estructura del pocma, sino el control y la presión a que deben ser sometidos los materiales de trabajo. La lectura de algunos poemas de Alberto Rubio, Rosenmann Taub, Pablo Neruda y Rosamel del Valle, demostrará - creo- que una conciencia alerta ante el control de la criatura poética y ante la carga emocional de sus elementos logró crear, en las composiciones de Rubio y Rosenmann, poemas que no sólo están mejor trabajados, mejor construidos que otros de poetas mayores, sino que poseen una densidad de pensamiento (y aquí no se trata de hondura de conceptos filosóficos), la cual está intimamente ligada a la expresión que muestra el vigor de su proyección emocional.

Y como la mayor parte de los poemas que escribieron nuestros poctas mayores están trabajados sobre la base de un verso libérrimo, vamos, tomando un ejemplo conocido, a esbozar, muy brevemente, el uso de este metro en esas composiciones, anticipando, si. que como ya rstamos a una buena distancia de los gritos histéricos que se lanzaron a favor de la poesía de Pablo Neruda (que me sirve como punto de partida para atacar el problema) y también a buenos kilómetros de los ataques que contra ella se enderezaron, procuraxé dax a mis palabras una objetividad que nada tendrá que ver con algunas opiniones que sobre él se han vertido: la de considerarlo el poeta mâs grande del muncto, como decia una persona cuyo nombre me reservo: la de estimar que es la poesia de un loco, cuyos versos no se "entienden"; la de pensar que es un mal poeta porque es comunista.

\section{VII.}

En lineas generales, Neruda utiliza el verso libre a partir de "Tentativa del hombre infinito". Lo que hace antes de ese libro es seguir, con más o

inconsciente". Y agrega: "Sólo un mal poeta podria acoger el verso libre como una liberación de la forma ... Ningún verso es libre para el que quicre hacer un buen trabajo". 
menos originalidad, las aguas de Dario - sobre todo en "Crepusculario"- y los poemas eróticos de Sabat Ercasty. Mís tarde, en los dos tomos de "Residencia en la tierra", salvo escasos poemas, continúa usando un verso que, a pesar de no ser completamente libre, pues suele aquietarse en metros tradicionales, sobre todo alejandrinos, puede considerarse libérrimo. Y este camino continúa hasta las "Odas elementales".

Creo no equivocarme al decir que la actitud de Neruda (y también la de sus compañeros de promoción), frente a este metro, que se usó durante veinticinco y más años, responde no sólo a que el poeta se sentía más a sus anchas dentro de su cauce: su actitud estaba mís de acuerdo con la supuesta libertad que el metro le consentia, y el versiculo le facilitaba un arma de batalla contra los poctas que lo habian precedido.

Pero su mundo, ¿se expresó en esa forma sólo por esas razones? ¿Logró crear, Neruda, algunas normas que dieran al verso libre la estructura necesaria para que las composiciones se sostuvieran por sí mismas? ¿Qué impresión se tiene hoy día de aquellos años y de la poesía que, sobre ese libre cauce, se cscribió entre 1920 y 1940? Y, por ńltimo, el pretendido rigor de que alardearon nuestros poetas en declaraciones sobre su arte, ¿se expresó a través de una conciencia lúcida que vigilara los materiales del idioma?

\section{VIII.}

A pesar de haber partido de Neruda para explicar la abundancia versolibrista, quicro hacer extensivas estas notas a todos los poetas que constituyeron su generación. No pretendo, por lo demás, que nuestros mayores debieran haberse expresado en metros tradicionales. Si no lo hicieron, las razones estaban a la vista: la poesia que los precedió tenia una escasa tensión dramática, era menor en el peor sentido de la palabra, y sus apoyaturas métricas (y junto con ellas, el pensamiento que acarreaban), poscian una muy pequeña fuerza, pues la forma era la manifestación retórica ( $y$ aquí sí que conviene emplear la palabra), de un pensamiento débil y clorótico. Pero al lanzar oleadas sucesivas sobre esa poesia menor, al romper (muchas veces por el solo afín de hacerlo) con leyes idiomáticas y formas usadas. aquellos poetas cayeron en experimentos que hoy nos parecen envejecidos.

El verso, diría Perogrullo, es sólo una pieza del pocma. Dentro de cualquier forma, es sólo un tornillo de la máquina que siempre debe ser: un organismo, por la perfección de su funcionamiento: una criatura con cabeza, tronco y extremidades. Pero un verso no estí aislado: se encuentra inserto en 
un cuerpo mayor que debe vivir, caminar y cumplir con todas las funciones de un ser vivo. Por eso, un buen poema no debe perder jamás de vista la estructura, esté realizado contra algo o a favor de algo. Si existen buenos poemas caóticos, no es por un desorden expresivo. Cuando Hart Crane, por cjemplo, toma una actitud frente al mundo industrial norteamericano, $y$ cuando expresa su desesperación ante la vaciedad espiritual del hombre contemporínco (pienso en su vasto poema "The bridge"), lo hace a través de una forma y de una arquítectura de gran perfección. Su poesía nada tiene de fícil: es más oscura que la de muchos versolibristas chilenos, y tan revolucionaria, tan original, en el buen uso del têrmino, que se la considera como una de las manifestaciones mis altas de la lírica norteamericana. De manera, pues, que en este sentido, ni oscuridad, ni claridad, ni hermetismo perdieron nada con una expresión justa y precisa: estín relacionados con el problema de la comunicación, tema muy interesante, pero que escapa al eje central de esta exposición.

Como Neruda y los poetas de su tiempo no participaron directamente de los modos surrealistas (Diaz Casanueva, en una declaración firmada en 1934, declara que él no participa de esas técnicas), tal vez los únícos poetas que tenian derecho a proclamar la informidad del pocma eran los que nos precedieron inmediatamente, vale decir, el grupo Mandragora, ya que, salvo el único núcleo central de la composición (liberación absoluta del subconsciente), no tenían por qué sustraerse al afín de vertebrar la obra, a pesar de que esa liberación no puede producirse, según creo, en forma total. Los poetas de la década del veinte no tenian esa disculpa, puesto que en sucesivas declaraciones proclamaron el rigor, la necesidad de una inteligencia ordenadora del caos, $y$, en fin, el hecho de que el poeta debia tener una lucidez absoluta para que el poema se mantuviera por sí mismo.

Si prescindimos, pues, de los surrealistas chilenos, y, en general, de la tćcnica surrealista, nuestros poetas manifestaron un solemne desprecio contra todo aquello que, de una manera u otra, estaba considerado como tradicional: metro, estrofa, rítmo, rima, estructura, puntuación, etc. Consideraron que los canales utilizados por ellos constituian la auténtica, la única poesia y que todo lo demás estaba en la prehistoria de ella. La insistencia con que a dos poctas de mi tiempo se nos ha tachado de estar metidos en la tradición de la poesía clásica española, cosa que, por otra parte, de scr verdad, scria un gran honor, incide en este aspecto del problema. Rubio, Rosenmann Taub o Uribe Arce han tomado contacto con elementos de regularidad estrófica, entre otras cosas, pero esto no significa que su modo de 
apreciar la realidad interna y externa de la expresión poética tenga nada que ver con una copia burda de la poesía española (de este siglo o de los otros). Ni la rima, ni el metro regular, ni ninguno de los apoyos externos de una poesia se relacionan con la nacionalidad: tienen que ver con el genio del idioma, de un idioma, en este caso, que hablan más de 100 millones de personas. Y tampoco, por supuesto, tiene nada que ver lo español con el fenómeno de la arquitectura, que no es monopolio de una poesia sino patrimonio del arte en general.

$\mathrm{Y}$ aquí es donde yo veo las diferencias que nos separan, pues me parece que el sentido de la composición, el control y la presión artística no tienen nada que ver, repito, con problemas de verso libre o de verso tradicional. Los nuevos poetas chilenos comprenden la importancia de una visión unitaria de la obra de arte (comenzando por el dominio del oficio) y el valor que tiene, para el uso de la poesía, la severidad de los elementos idiomáticos empleados, no importa cuál sea la altura del pensamiento. $\mathbf{Y}$ creen, además. que sỉ ese ideal de la forma (inseparable del contenido) se presenta de un modo chapucero, la criatura poética es nonata."

IX.

En muchas ocasiones me he preguntado por qué la poesía nerudiana produjo una secuela de tantos poetas mediocres o menos que mediocres, los cuales siguieron esas aguas, dentro de la poesia chilena y fuera de ella, sin producir ni un solo valor, ní una sola poética de categoría. Naturalmente, yo no mido a un pocta por el mayor o menor caudal de sus seguidores; pero creo que hay una respuesta a esta pregunta: la poesia de Neruda -informe c incitante- no requiere, de parte del seguidor, ninguna disciplina, ni de artesania ní menos de ascética, porque su falta de estructura incita a scguir un río que no corre por ningún lecho y que nunca se sabe dónde desemboca. Fs fácil comprender entonces por qué sus imitadores se difundicron tan profusamente, y por qué jamás pudo scĩalar caminos. Su mundo caótico (que no se ha modificado a partir de "Residencia en la tierra", pese a sus incursiones en el paisaje americano $y$ a sus vueltas y revueltas sobre la cosas materiales) sigue, a mi entender, incidiendo en un problema de rigurosidad ante los materiales que tenia a la mano. Desde luego, no voy a decir que

"Se es artista - observa Nietzchea condición de sentir como un contenido, como la cosa misma, lo que los no artistas llaman la forma". 
Neruda haya carecido o carezca de oficio: me parece que, de su tiempo. es el que tuvo mayor preocupación por resolver el destino de sus obras. Pero tanto las expresiones coloquiales (derivadas en parte del habla chilena, y en parte de la jerga periodistica), como la sintaxis y el uso del material lingüístico (su castellano parece una mala tracucción del inglés), que Neruda utiliza a lo largo de los poemas de "Residencia en la tierra", no fueron usados de una manera consciente, y entraron en su expresión de contrabando para restar propiedad a clla. En otras palabras (y al revés de lo que ocurríb en la obra de César Vallejo, cuyas tomas de contacto con el habla peruana siempre estuvieron colocadas sobre una conciencia lúcida), los elementos de 1a realidad inmediata del idioma que rodeo a Neruda, llegaron a el y lo invadicron, sin que se percatara el poeta de ello. Su modo formal de expresarse (esto es, el modo versolibrista) estuvo lastrado no solo por defectos de composición: la incorporación de los elementos coloquiales en el léxico nerudiano, respondió a la misma necesidad con que Neruda se sirve de un pensamiento sintáctico-racional nada riguroso. Esta falta de propiedad se debe a que el fín estético que en apariencia se habria propueto el temperamento nerudiano no es un fin estético. No hay una persecución de la forma, y. por esta razón, el pensamiento sintáctico-racional no está llamado a ser ni cxacto ni severo. En el "Canto General" sí hay, aparentemente, lo que no cxiste en "Residencia": una finalidad concreta, plística y establecida, es decir, cantar, hacer la exégesis del continente. Existe el objeto: la expresión se pliega, con mayor facilidad, a su temperamento, y parece que hubiera llegado a una completa unidad de pensamiento y expresión. Pcro no es así, pues la retórica del "Canto General" es especulativa: es una aplicación de fantasias del inconsciente desarrolladas antes en "Residencia", cuyos términos y valores se vuelven a aplicar aqui en forma deliberada y artificial.

Pero Neruda no es un ejemplo aislado.

$\mathrm{x}$.

¿Por qué ese affín por desconyuntar el material poćtico? ¿Es acaso ésta una caracteristica de la poesía de lengua española que se escribe en América?

-Aunque lo trate de justificar desde el punto de vista que desarro110 en "Residencia en la tierra", siguen teniendo plena validez las observaciones que Amado Alonso hace en el capitulo V de "Poesia y estilo de Pablo Neruda" (segunda edición argentina), en las cuales el investigador español pone de manifiesto la impotente situación del poeta frente al rigor del idioma. Véase, además, la nota 8. 
¿Es problema de la lirica americana en general, fruto, tal vez, de las tiradas whitmanianas? $\mathrm{Y}$, finalmente, para volver a una palabras anteriores, cel hecho de que se escriba en verso libre significa que este metro carezca de unidad? ¿No se ha abusado de êl de tal manera que hay momentos en que no se sabe por qué se ha escrito en verso y por qué no se ha vuelto, simplemente, a la prosa?

En este desencaje de las unidades métricas antiguas prevaleció, en primer lugar, un criterio deliberado y confuso. Preocupados los viejos poetas chilenos por abrir su campo, experimentaron con las innovaciones que en el ímbito de la poesía europea (piénsese en Arnold, Claudel, Laforgue, etc.) crearon los poetas franceses e ingleses, apoyados, un si es no es, en los versículos whitmanianos; $y$ en este trance, no solo perdieron de vista, al avanzar por el camino, el hecho de que el verso libre debía contar con obligaciones tanto más grandes que las que abrazaban las formas de la tradición: olvida ron que el poeta hallábase en la necesidad de elaborar leyes propias para sus nuevas criaturas, y que éstas tenian que entrar a someterse a leyes, todo lo nuevas que se quisiera, pero leyes al fin $y$ al cabo.

Hay una oscuridad poética que deriva de la extrema precisión en el uso de los materiales con los cuales está trabajado el poema. Y hay otra, la cual proviene de la imprecisión en el empleo de ellos. Pero la confusión comienza cuando el poeta, al tratar de trasladar en una forma virginal (la palabra vale en este caso) su expresión interna, prescinde de un primer plano (la imaginación auditiva, e incluso, la música, cuando ésta, desde luego, no existe aparte del significado) y deja en ayunas al lector de ese primer peldaño. En otras palabras, cuando el poeta se satisface con verter la vivencia sobre la palabra escrita sin la necesaria acomodación, o cuando se contenta, por otro lado, con llevar el caos de la vida a la obra, creyendo que el reflejo fiel del caos es simplemente arte caótico.

XI.

Frente al problema de la creación, y, sobre todo, fiente al problema, en este caso, de la expresión libérrima, no existe, paradojalmente y a pesar del adjetivo, libertad. Una de las primeras nociones que debe grabarse en la cabeza un poeta, es que, ante la hoja en blanco, todo es tropiezo. No se da, pues, una expresión caótica, escribiendo poemas que no tienen estructura, ni ritmo, ni espina dorsal, y que carecen de esa precisión que requiere - no importa las formas usadas- todo organismo artistico. 
Prescindamos de que en uno de nuestros poetas mayores - Pablo de Rokhanos guste o nos deje de gustar su "chilenidad", su prosaísmo retórico, su "americanidad" o su inflado gigantismo". Lo que succde en ell (y esta observación ha sido hecha no por compañeros de mi promoción, sino por muchos observadores imparciales de la poesia), es que, frente a sus materiales de trabajo, nunca supo discernir dónde comenzaban y dónde terminaban sus límites. De esta manera, pues, como en muchos poemas de Neruda, se amontonaron detritos y escorias que no solo restaron unidad a la composición, sino que permanecieron como piezas sueltas. Ahora bien, ¿significa esto que se dio salida a una expresión caótico-interna, y que lo desmesurado del desarrollo hizo olvidar el hecho de que falten algunos elementos de ese organismo que tiene que ser siempre un poema?

Y esto es lo que sucede en Huidobro, Diaz Casanueva, Rosamel del Valle y Neruda, Las excepciones estarian en ellos mismos: en el Diaz Casanueva, de "Réquiem": en el "Orfeo", de Rosamel del Valle, y en los últimos poemas de Huidobro (una de las composiciones que escaparian a este defecto, es el "Monumento al mar"). Lo que en estos ejemplos levanta, amarra la estruetura de la pieza no es la unidad espiritual (que no la tienen): es el impacto de la experiencia que cuajó en un trabajo elaborado con vista a la totalidad del poema, sin abandonar los tornillos mis pequeños de la obra. Pero cuando en la mayor parte de las obras de estos poetas se prescinde no sólo de los elementos rítmico-auditivos, sino, lo que es peor, cuando la metífora se gasifica, se destruye y aparta de su función primordial, cual es la de referir al lector a un objeto determinado. físico o espiritual, que debe estar intimamente unido al núcleo de la pieza: me parece que la unidad del poema estí rota. La metífora, cuando se presenta sin esa función, se transforma en metífora formal, simple artificio que no responde a ninguna realidad. Pues los valores ritmicos, por otra parte, lejos de ser un mero ornato del poema, se funden con él c invaden su cuerpo: toda la composición debe responder en su totalidad, de tal manera que la falta de un valor resta precisión a los otros.

XII.

No es necesario hacer ahora la historia del verso libre, porque nos llevaria mucho tiempo. Pero colocados los poetas contemporíneos ante la posibilidad ${ }^{\circ}$ Caso muy distinto, por ejemplo, el desborde de Thomas Wolfe. que la abundancia whitmaniana o 
de trabajar con un metro nuevo, o por lo menos relativamente nuevo, crearon, al comienzo, para su uso personal, algunas normas que contribuyeron a darle unidad, no importa cuintas expresiones heterogéneas colocaran en sus composiciones.

Al prescindir de la rima, aunque no de los elementos rítmicos, el versículo tenia que buscar, por una ley que aborrece, en el proceso creativo, el vacio de la informidad, algo en que pudiera apoyarse: un esqueleto, en fin, una espina dorsal que lo sostuviera y que apoyara, al mismo tiempo, la expresión emocional. La rima, al fin $y$ al cabo, no es más que el reiterar, al final del verso, en medio de él o en cualquier otra parte de su cuerpo, una misma terminación, pues pone de relieve el ritmo intensivo, del que subraya los tiempos principales. El empleo de técnicas semejantes a las que usa la música (variación de los temas, recapitulación de ellos, exposición de motivos que luego se han de recoger, ete.), la utilización de la anífora y de conjuntos estróficos, dentro de los cuales suben y descienden corrientes que siempre se refieren al centro del cual partió el poeta, son algunos de los reemplazantes de la rima y contribuyen a ligar la obra. Hay en Neruda un ejemplo que no se prodiga, y que nos puede dar alguna luz sobre los recursos antes citados. Se trata del poema "Barcarola", Si esta pieza posee mayor unidad que otra de Rosamel del Valle, "La cabeza solitaria", no es porque el pensamiento de éste sea mâs profundo que el de aquél, sino porque Neruda supo (en algunos pocos poemas de "Residencia en la tierra", se ha dado cuenta de ello) dotarlo de una precisa arquítectura, de un movimiento ascendente y descendente, elaborado sobre la base de la reiteración de bloques estróficos, y porque el de Rosamel del Valle, que no posee ni unidad intelectual ni propósito definido (que es lo que sucede en la mayor parte de su obra). pierde, al desmembrarse en una serie de elementos alejados del supuesto núcleo del poema (que es el de - así parece - la soledad humana), la concentración, y porque los medios que lo componen no se relacionan ni remotamente al propósito inicial. Y hablo, desde luego, de un enlace poético".

"El pocma de Rosamel del Valle ha sido tomado al azar de su último libro, "La visión comunicable", Edit. Nascimento, Santiago de Chile, 1956. La revisión de toda su poesia, salvo momentos aislados, me permite afirmar que "La cabe. za solitaria" no constituye una isla dentro de su obra. En "Barcarola", poema de Neruda, inserto en "Residencia en la tierra" -analizado agudamente por Amado Alonsoexiste lo que no hay en la pieza de Rosamel del Valle: unidad y equilibrio en el empleo de todos los elementos que necesita una obra de arte. Veamos la composición del poeta de "Orfeo": 
No hay falta de audacia en los nuevos poctas chilenos, por el hecho de que, apoyándose en elementos unitarios y rítmicos, e incluso, empleando formas tradicionales, hayan vuelto a cantar cosas que no tuvieron crédito hace treín. ta años o más. Lo que han hecho y lo que hacen ahora, no es menos revolucionario que lo que hicieron los poetas mayores de Chile. No han tratado de hacerse más claros por prejuicios politicos, y menos han creido que dar

No es absolutamente necesario [abandonar a los fantasmas acostumbrados ya a permanecer [con nosotros ni seria Justo desdeñar sus conversaciones. [Aún sus amenazas

No nos perturban demasiado pues-

[to que de todos modos No son sino criaturas en busca [del sol por las alfombras, ¿X qué diferencia hay entre perso. [sonas $y$ fantasmas? Cuando lo quieren, son tan terri[ble unos como otros. Aunque lo verdaderamente terrible son los [aromas que nos caen

Al levantarnos. Como lo bello es lo [que no se desprende del todo

De las visitas que nos acompañan. [Como no hay tampoco otra ciencia Para quienes descleñan a los so[námbulos. Con Una educación así se es sabio y [los crisantemos

Se dejan operar con facilidad.

Recordemos ese mundo donde tú [y yo somos lo que no es. Guardo todavia el ramo de mirtos [olvidado en la cerradura Tan odiada por los huéspedes ese [año. Detrás de cada cosa Se escondía lo que ellos llamaban, [digamos, amor ardiente. Habian oido hablar de ese discur[so. Pero tú decias: "Cuidado
Con el mar que hay debajo del le[cho". Naturalmente, Asi se escriben los epitalamios. "De [todos modos, Me gustaria olvidar primero y [amar después. Eso es la vida intensa". ¿ $\mathbf{Y}$ hay quién no [hable

de intensidad en estos tiempos?

\section{No olvides}

Recordarme que debo morir. No [olvides recordarme cualquier cosa, $\mathrm{Ni}$ insistas en creer que ya no hay [honestidad para morir.

No veo la necesidad de llevar man[chada la piel ni de cultivar [a]gunos granos

Para dar a las palabras esa lucidez [que todos ansian.

Vi una vez a una mujer con las [manos

Sobre las rodillas y eras tú a las [cuatro horas. No sabria decir hacia dónde mira-

[ba, porque Yo estaba lejos. Tal vez en ese [reino [chamos.

¿Has visto a alguien en preparati[vos para deshacerse? Algunos creen haber limpiado el [camino $y$ ofdo la bienvenida Cientificamente preparada para [después del eclipse. 
cuenta de lo americano es escribir sobre realidades fisicas de América, porque para hacerlo hay que dar cuenta, antes que nada, de una problemática espiritual (de cualquier naturaleza que sea), y, luego, pero en muchísimo menor grado, de una actitud ante los hechos fisicos de nuestro continente. Y tampoco hay menor densidad de pensamiento si a una mayor unidad artística corresponde la utilización de viejos temas.

El decoro, por supuesto. Pero el [cuerpo se reseca Aún cuando se le rieguen como a [las buenas ideas O a los geranios. Y los geranios [son las horas Que todo reloj pierde sin que se [lo ordenen.

Lo único que ha sucedido es que [existes.

Yo debo haber hecho ya mi tiem[po, porque todavia Sé mirar al través de los huesos [de la noche.

Y si no fuera por decoro diría que [las hortensias Florecen a causa de lo que se con[versa en el jardín "Permitame, señora, clavar un al[filer en sus malas ideas. Porque se habla del corazón cuan[clo ya es tarde. Cuando La resolana es una leyenda en los [corredores

De la casa abandonada". $Y$ existir [es justamente

El sabor a ceniza que se enciende [en la lengua al despedirse.

Mas lo que no ha sucedido es que [se borren los jeroglificos de [mis manos.

Mientras tanto lo por suceder lo [está diciendo a toda hora Tu mirada fija en el sol sin fin [de mi cabeza.
Porque nada es ni nada será sino [como tú quieras.

Tú, $\tan$ distinta $y$ tan parecida a [tantas cosas Sin que ni yo mismo sepa exacta[mente lo que eres.

A lo largo de la composición predomina un metro irregular que fluctua entre 17 y 21 silabas. Hay algunos - pocos- versos que terminan en silabas agudas, aunque no se ve con claridad por qué están cortados donde los scparó el poeta. El poema no posee ninguna estructura que lo amarre, debido, entre otras cosas, a la falta de materiales ritmicos y a la ausencia de bloques estróficos que impulsen el movimiento total de la pieza.

"La cabeza solitaria" puede dividirse en doce partes, cuyo conjunto tampoco posee un eje claro $y$ definido.

En la primera parte, que comprencleria hasta el verso séptimo, se habla de la absoluta semejanza que hay entre hombres $y$ fantasmas: pero cada uno de estos siete primeros versos se desintegran en una serie de pensamientos que tampoco poseen unidad: "fantas. mas", "conversaciones", "amenazas", "criaturas", y el adjetivo "terrible" tratan de encadenarse $s i n$ resultado.

En la segunda parte-versos oc. tavo y noveno- hay una referencia a los aromas (cuya correalidad se- 
Pero esclarezcamos bien qué entendemos por tema. No se trata de "contar" algo en la poesía: el tema no es sino lo que, reiterado, da unidad al poema, otorgándole un equilibrio y amarrando el conteniclo. Cuando Alberto Rubio escribe sobre una abuela muertat, parte desde lo que podriamos llamar anéc-

ria lo que dejamos de ser en el sueño, es decir, como dice el poeta "lo verdaderamente terrible son los aromas que dejamos al levantamos").

En la tercera parte-versos no. veno y décimo- se vuelve a fraccionar la composición en otro estrato que no posee relación poética con la parte precedente.

Las partes cuarta (pensamientos sobre la usura: v. 10-14); quinta (digresión sobre la nada: v. 15); sexta (lo que los seres humanos dejan: v. 16-24) : séptima (el problema de la mucrte: v, 24-26) : octava (la piel física del hombre: v. 27-28); novena (se habla de una mujer que espera: v. 29-33): décima ("El decoro, por supuesto", o sea, lo superficial de la vida humana): décimoprimera (caducidad del cuerpo, esto es, el tiempo simbolizado en el geranio, que repre. senta el tiempo perdido: v. $37-40$ ) y décimosegunda (problemas del tiempo, simbolizado, en este caso, por la hortensia y por las rayas de las manos. "jeroglificos de las manos": v, 41-56); todas estas partes, en fin, con sus núcleos particulares descoyuntados, los cuales no poseen ninguna relación con el posible núcleo central del poema, que seria la soledad del hombre, contribuyen no sólo a que toda la pieza pierda la unidad rítmico-interna sino, lo que es peor, hace que carezca de propósito definido, de esos aceleramientos y retrocesos que un poema no puede (para crear la unidad auditiva) dejar de tener.

Una rápida mirada a todo el poema (igual cosa ocurre con otras composiciones de "La visión comunicable") nos dejaría ver cómo cle. mentos coloquiales se han introdu. cido inconscientemente en su organismo, con una monotonia que linda en la pobreza expresiva, la cual nada tiene que ver con la simplicidad de expresión. Por ejem. plo: "no es absolutamente necesario", "ni sería justo". "puesto que de todos modos". "lo verdaderamente terrible", "como no hay tam. poco", "con una educación asi". "habian oido hablar", "no olvides recordarme", "ni insistas en creer", "no veo la necesidad". "lo único que ha sucedido", "lo por suceder", "sino como tú quieras", etc. Otra mirada descubriria también que la pobreza expresiva deriva, ade. más, de la monotonía del empleo de los adverbios acabados en "mente": "absolutamente", "naturalmente". "cientificamente", "justamente". "exactamente".

No colecciono faltas. Pero cuando se alardea de rigor y de inteligencia ante el fenómeno poético, y cuanclo se nos reprocha no tener ideas claras sobre el material idiomático que el poeta debe usar, se hace necesario ver si los viejos poctas chilenos poseen lo que, segín ellos, nosotros no tenemos.

"La abuela" -tal es el título del 
dota o también tema simple; pero su alcance, su golpe no sólo se eleva sobre la dimensión puramente física de la muerte: gira alrededor de ella, y la supera. ¿Y es menos revolucionario, menos profundo que Rosamel del Valle, - Vicente Huidobro? ¿Qué importancia tiene, en fin, que Rubio haya empleado una forma antigua - el terceto alcjandrino- y en qué forma ha disminuido el valor de la composición? Su pensamiento, zees menos denso por haber Rubio comprendido que jamis un poema disminuye su alcance si,

poema de Rubio- pertenece a su primer libro, "La greda vasija", Santiago de Chile, 1952. El texto es el siguiente:

Se puso tan mañosa al alba fria, la cerrada de puertas, la absoluta [de espaldas. cosiénclose un pañuelo que nadie [conocía. Se bajó bien los párpados. Con in[finita llave los cerró para siempre. Unos ne[gros marinos vinieron a embarcarla en una ne. Igra nave. Y la nave, de mástiles de esper[mas y de velas de coronas moradas de flores, era [el barco que lleva a extraños puertos a las [hondas abuelas. No hizo caso a nadie: ni a la [hija mayor ni a su eterno rosario: tan maño[sa se puso. tan abuela recóndíta metióse en [su labor. Ni el oleaje de rostros, ni la llán[tea resaca pueden ahora atraer su nave hasta [esta costa: ini nadie de su extraño pañuelo [ahora la saca!

El poema recuerda el mito grecolatino de la barca de Caronte. Las velas de esperma se han trans. formado en las velas de un barco. Rubio no pierde, en ningùn momento, el núcleo central de la composición (la mucrte de un pariente) alrededor del cual ha tramado sensaciones familiares, $y$ también, expresiones del habla chilena ("se puso tan mañosa", "no hizo caso a nadie". "tan mañosa se puso". "ni nadie... ahora la saca") : sólo que aquí esas expresiones entraron a iluminar $y$ cargar de emoción la pieza y se justifican no sólo por lo medido de su uso sino también por la conciencia con que están utilizadas. Las fuentes que corren alrededor del rio central del poema (muerte de la abuela) siempre se mantie. nen unidas a el y terminan por desembocar a su orilla. La composición no sólo mantiene la unidad debido a la luciclez con que están usados los elementos familiares que se hallan alrededor del poema: logra sostenerse porque también el vehículo sobre el cual van (tercetos alejandrinos) estí plenamente logrado. Una lectura de los otros poemas del libro revelaría una misma conciencia y un mismo rigor,

En otro poema - se trata de "Añonuevo", inédito aún- de David Rosenmann Taub, podríamos ver, a través de un análisis some- 
a un contenido escatologico, trabado con la apoyatura exterior, corresponde una superficie de valores rítmicos usados con gran control artístico? $\mathbf{Y}$ yéndonos hacia otro lugar del mundo, aunque no pretendo establecer comparaciones, ¿en qué un soneto o una pieza como "Fern Hill", de Dylan Thomas (y este último poema participa de valores estrictamente narrativos), es menos revolucionario, menos profundo que "East Coker", de Eliot? Ni el tema, pues, ni la forma tradicional del soneto inglés, ni los elementos rítmicos quitan nada a la calidad de la obra. Cuando un poeta presenta sus poemas con una gran perfección de forma y no logra producirnos ningún ramalazo emocional se debe a que su contenido (hablo de contenido, repito, solo para entendernos) es pauperrimo, porque se esconde y se disfraza detrís de un oficio, que es pura exterioridad: sus obras están escritas con la mano izquierda, y es un simple versificador. Pero el versificador puede darse, y se da, en la poesía versolibrista, y puede haber en ella tanta escoria como en la de otros siglos. De manera que no hay tiranía en la expresión de otros tiempos, ni libertad en el verso libre. Lo demás es prejuicio, del cual parecen no haberse desprendido los poetas de la década del 20.

Ahora bien, todo esto no es un problema formal para los nuevos poetas chilenos. Forma y contenido no están separados. Cuando un poeta escribe un soneto no lo ha elegido con anterioridad de forma, porque ésta no se halla

ro, caracteristicas semejantes: en este caso, los materiales reiterativos del estribillo ("por los que ya no están y fueron nuestros") están trabajados conforme a una técnica de variación, la cual produce, por la lucidez de su empleo, un golpe emocional de mucha hondura. La sensación de la imposibilidad de volver al pasado, junto con la partida de los seres queridos se unen a una gran destreza técnica, la que no se queda en pura exterioridad: el poema funciona como un todo. Doy, a continuación, el texto:

Ah, ganas de llorar, ganas tremen[das de llorar. ¡Largo afán de turbu[lentos alaridos que me destroza el pecho! Ah, borbotón, llorar, poder llorar.
Por los que ya no están y fueron [nuestros crece el abrazo, madre, en los so[1lozos.

Pero no puedo, llanto. Retener[sel...

IEs necesario revolcarse dentro!

iSi, madre se da cuental No. No [puedo.

Debo escarcharte, 1lanto, iy sopor[tar!

Por los que ya no están y fueron [nuestros crece el abrazo, madre, en los so[llozos. ¿Que el añonuevo de la pesa[dumbre se abalancel El abrazo! |Agarra[dero desesperadol Madre, estoy contigo. 
preestablecida en la creación. El poeta sabe, intuitivamente, que debe emplear una forma y no otra, y, si, en lugar del soneto, le hubiera sido necesario usar el versiculo, por ejemplo, no habria vacilado en hacerlo. El verso libre queda como uno de los medios que entregó la poesía contemporánea. Y volviéndonos a la temática empleada por los viejos poetas, no veo por qué sea de mayor profundidad que la nuestra. Podemos (y voy a emplear el plural para incluirme) escribir sonetos, trabajar con el verso libre, remansarnos en antiguos maestros, con una herencia procedente (y esto quiero señalarlo muy bien y con mucha claridad) no sólo de los poctas chilenos, puesto que el campo de nuestra mirada está muchísimo más allá de las fronteras fisicas.

Los poetas jóvenes conocen algo más que nuestro mundo chíleno. No pretendemos haber dado siempre en el blanco; pero tratamos de alcanzar el rigor de la palabra poética, la cual vive en el océano idiomático, nadando en un idioma que, como el castellano que se habla y escribe en América (por su carácter provisional), obliga al escritor, y con mucha más razón al poeta, a mantenerse con una conciencia lúcida y alertas.

1Por los que ya no están estoy

¿Aro de aromas? ¿Despojos?

[contigo!

¿Algún alga que vuelve a pedirnos

[perdón?

¿Hemos nacido? ¿Rumbos de ex[traviados retoños?

¿Apenas un clamor

de pavesas? ¿Cinceles

de un campo que se yergue?

Abrázame, delirio, Madre, abráza-

[me.

Abrázame, asi, „fuertel, una vez

[mâs.

Arrayán. Musgo altísimo,

Traspasando el dogal de esclavitu-

los navios invaden

[des,

el diamante del polvo.

Las anclas cantan sobre las espinas.

Por los que cortaron las amarras, por los que nos amaron y se fue-

[ron

crece el abrazo, madre, en los so-

[llozos.
La noche. El viento. ¿Huellas?

¿Quién, como mar de mares, nos

[acerca?

Por los que ya no son nuestros y [han partido, por los que ahora la tierra abraza [fuerte, abrázame en la tierra una vez más.

Por los que en lo profundo nos [abrazan, abrázame, así ,fuerte!, madre mia. ...Mira, madre, esa roca: la arbo[leda rompe en ella celajes y praderas. "El poeta americano que habla español debe saber que su idioma es un cuerpo provisorio, en trance de evolucionar. Esto le obliga a tener una conciencia agudísima en el $\mathrm{cm}$ pleo de su palabra poética; pero, claro está, esto no lo autoriza a usar una expresión que desconozca la sintaxis de la lengua que escribe, la cual sintaxis puede romper- 
se siempre que exista conciencia de esa ruptura.

La abundancia del gerundio en Pablo Neruda es asombrosa. En "Residencia en la tierra" aparecen algunos como éstos: "poblándose", "teniendo". "pesando". "Haciêndose". "rodando". "existiendo". "mezclando", "deteniéndose". "saliendo". "cantando". "extendiéndose", "estirando" (Galope Muerto); "sepultándose", "atardeciendo", "huyendo", "accchando", "haciendo", "golpeando". "destruyendo" (Alianza); "Horando". "quemando", "llorando". "lloviendo", "Echando", "mordiéndose". "sonando" (Barcarola): "durando". "llorando" (No hay olvido). A lo largo de todo el libro, el gerundio se prodiga hasta la saciedad, $\sin$ ainguna discriminación, y desde luego, sin ninguna conciencia. No creemos, como afirma Amado Alonso, que este empleo responda a una necesidad violenta de expresión por parte del poeta: creemos, por el contrario, que la abundancia de su uso incide en la falta de conciencia con que Neruda lo emplea, pues se convierte en una muletilla agobiadora. Cierto es que el gerundio usado de esta manera puede otorgar al verso un fluir lento, hermoso y hasta extrano, pero siempre que se emplee con discreción y con lucidez. He contado (tampoco por un prurito de minuciosidad) más de 200 gerundios en "Residencia en la tierra", muchos de los cuales no son sino una mala traducción del inglés: "mares poblándose". "campanadas... teniendo" "una hora... extendiéndose" "los grandes zapallos... estirando". "hojas sin sonido... sepultándose", "el sol aban- donado atardeciendo". "los dias acechando", "tus besos haciendo". "las olas destruyéndose", "llamas húmedas quemando". "al sonido (del corazón) lloviendo", "una botella echando espanto", ctc.

En los poetas de la generación del año veinte - por ejemplo, Rosamel del Valle, Díaz Casanueva, Pablo de Rokha- ocurre algo semejante: "mi boca ... bebiéndoles el micdo" (Orfeo, II parte) ; "en forma de trigo ardiendo" (El hombre devorado), etc., en Rosamel del Valle. En Diaz Cisanueva también se descubren gerundios empleados a la inglesa, como por ejemplo, en una declaración sobre "El blasfe. mo coronado", escrita en prosa: "cubre de interrogaciones su yo inmenso y destruye la ilusión del sujeto racional "jugando" al mundo": o en algunos de sus pocmas: "le asoman emergiendo de la nada" (Elevación de la sima) "silencio situando" (Seguridad del sondmbulo): "venas inflamadas corriendo" (Seguridad del sondmbulo), "lígrimas revelándose" (El Blasfemo Co. ronado), "el ser revelándome" (Blasfemo, parte cuarta). En Pablo de Rokha se prodiga con una abundancia semejante a la de Neruda. En Huidobro escasea el gerundio mal usado, aunque no falta; pero se han introducido en su expresión formas galicadas que se repiten hasta la saciedad: "es para llorar que...", "es ast que...". "alli fue que...". etc.

Esta critica no importa un rechazo a las expresiones extranjeras que puedan introducirse en el idioma empleado por el poeta, siempre que ellas aporten elementos positivos que enriquezcan la forma. 
Desde Pablo de Rokha hasta Rosamel del Valle, todos los poetas mayores han insistido, con énfasis, en el rigor $y$ en las leyes que debe posecr el poema. Es más: se consideran los descubridores de la técnica poética, sutil, esotérica e incorruptible; pero se han amparado en ellas para vaciar sus torpezas verbales. En una declaración de arte poética, Rosamel del Valle, habla de "ley", de "esfuerzo de inteligencia", de "control vigoroso". Pero dice, por ejemplo, en "País blando y negro": "Entonces viven las palabras en mi memoria. Vuelven los anchos planos de lo mágico. $\mathbf{Y}$ de ninguna manera estos hechos aparecen como un simple encadenamiento de cosas sucesivas a las que haya de darles una interpretación" (nótese la anfibologia).

Los viejos poetas hablan -es su truco- con la naturaleza del que conversa claramente sobre todas las cosas; sorprenden al lector hablándole con la misma sencillez con que se dicen o se refieren todas las historias banales; pero escamotean la historia: ponen, en vez de algo que se desenvuelve según las reglas clásicas de la 16 gica, incoherencias, motivos absurdos. De esta manera, lo "fantístico" se torna más fan. tástico: lo "irreal" participa, fraudulentamente, de lo real; la "poesia", de la prosa; la "imagen", de la palabra. Lástima que no se hayan dado cuenta que, para consumar el truco, les hace falta, desde luego, la palabra, el buen sistema sintáctico en el que ella se "traduce".

$Y$ no es cuestión de simple ignorancia de la gramática: es el mal gusto y la vulgaridad inextirpables.
Por ejemplo: "La habitación, des. poblada o no, guarda una presencia muy distinta a la realidad de las cosas, muy distinta a lo que no es sino la aparente realidad de las cosas". Distinta... ¿a la ... o de la realidad de cosas? (Pais blanco $y$ negro). Otro ejemplo: "la luz que parece leche y el trueno de miel" (Pais blanco y negro). Por cierto, la incorrección "trueno de miel" no es deliberada; "miel" no califica a "trueno": quiere que el "trueno" sea "miel", como la luz "parece" leche, La construcción sintáctica está, pues, frustrada. Otro ejemplo: "No tan cerca, por supuesto, ni tan hecha de olas como ciega" (No lo que se dice). No tan cerca, ¿de qué, o de quién? E1 prosismo sintáctico "por supuesto", no implica nada. "Ni tan hecha de olas como ciega" no tiene ni pies ni cabeza. ¿Quiere decir que las manos (el verso anterior: "casa de ceniza sobre una flor y una mano") si son olas, son, además, $y$ sobre todo, ojos ciegos? Aunque se coloquen los elementos que le darian a la frase coherencia gramatical, el resultado es nulo. No se ha expresado nada.

Diaz Casanueva confiesa "que la poesia es para mi, ante todo, una disciplina" (prólogo a la selección de sus poemas hecha por Eduardo Anguita y V. Teitelboim): pero en "Elevación de la sima", hay cosas como éstas: "tal vez porque es. tos... tiran de la nada; esa parte mia que todavia tengo ..., no consigo aún a costa de ...; la unidad de mi ser no consigo aún a costa de su propio destino". Parece todo un ejercicio (mal hecho) de traducción. 